\title{
Dating and synchronizing paleoclimatic records over the last interglacial
}

\author{
Emilie Capron ${ }^{1}$, A. Landais ${ }^{2}$, P.C. Tzedakis ${ }^{3}$, E. Bard ${ }^{4}$, T. Blunier ${ }^{5}$, D. Dahl-Jensen 5 , T. Dokken ${ }^{6}$, R. Gersonde ${ }^{7}$, F. Parrenin ${ }^{8}$, M. Schulz ${ }^{9}$, B. Vinther ${ }^{2}$ \\ AND C. WAELBROECK ${ }^{2}$ \\ 'British Antarctic Survey, Cambridge, UK; ecap@bas.ac.uk \\ ¿Laboratoire des Sciences du Climat et de I'Environnement, CEA Saclay, Gif-sur-Yvette, France; ${ }^{3}$ UCL Department of Geography, University \\ College London, London, UK; ${ }^{4}$ Centre de Recherche et d'Enseignement de Géosciences de l'Environnement, Aix en Provence, France; ${ }^{5}$ Depart- \\ ment of Geophysics, University of Copenhagen, Denmark; ${ }^{6}$ Bjerknes Center Centre for Climate Research, Bergen, Norway; ${ }^{7}$ Alfred Wegener \\ Institute, Bremerhaven, Germany; ${ }^{8}$ Laboratoire de Glaciologie et Géophysique de I'Environnement, Grenoble, France; ${ }^{9}$ MARUM, Center for \\ Marine Environmental Sciences, and Faculty of Geosciences, University of Bremen, Germany
}

\section{We review some of the available strategies for a coherent dating of ice, marine, and terrestrial records from various latitudes over the last interglacial.}

W ithin the Past4Future project, specific efforts are dedicated to the improvement of absolute age scales and to the synchronization of climate records from different archives and different latitudes. A specific committee has been set up to develop guidelines for dating and synchronization to help with synthesizing and integrating results from the Work Packages that produce and compare the datasets.

While the Holocene is relatively well dated, the last interglacial (LIG) lasting approximately from 129 to 118 ka BP, has been attributed different durations depending on the considered records (e.g. Kukla et al. 1997; Shackleton et al. 2002). These differences result from regional disparities and dating inconsistencies (Dutton and Lambeck 2012). Building a reference timeframe for the LIG is thus essential to disentangle climatic external forcing and internal feedbacks as well as to depict the regional sequences of events.

Here, we review some of the existing absolute constraints and synchronization strategies over the LIG for providing a coherent stratigraphic framework to present paleoclimatic records. We also provide an example of developing a common timescale for marine and ice core records over the LIG using approaches discussed below. The list of age markers discussed hereafter is not exhaustive but the complete document established by the Past4Future dating committee is available at http://www.past4future.eu/ index.php/resources/project-resources (M5.1.2 Workshop: Integration of results, 2012)

\section{Absolute age markers}

Speleothems provide absolute ages of climate events thanks to dating methods based on Uranium-series. For example, the largest increase of the Asian Monsoon activity (as reflected in the Sanbao speleothem abrupt calcite $\delta^{18} \mathrm{O}$ decrease) over the penultimate deglaciation (Termination II) occurred at 129 ka BP with an associated error of less than 100 years (Cheng et al. 2009; Fig. 1E). For European speleothems, less abundant in Uranium, dating constraints are usually less precise (e.g. Genty et al. 2003).
The upper parts of ice cores in high-accumulation areas can be dated by identifying and counting annual layers (e.g. Svensson et al. 2008). However, ice cores lack deep and old absolute dating horizons except for tephra layers. To date, only the absolute dating of the tephra from

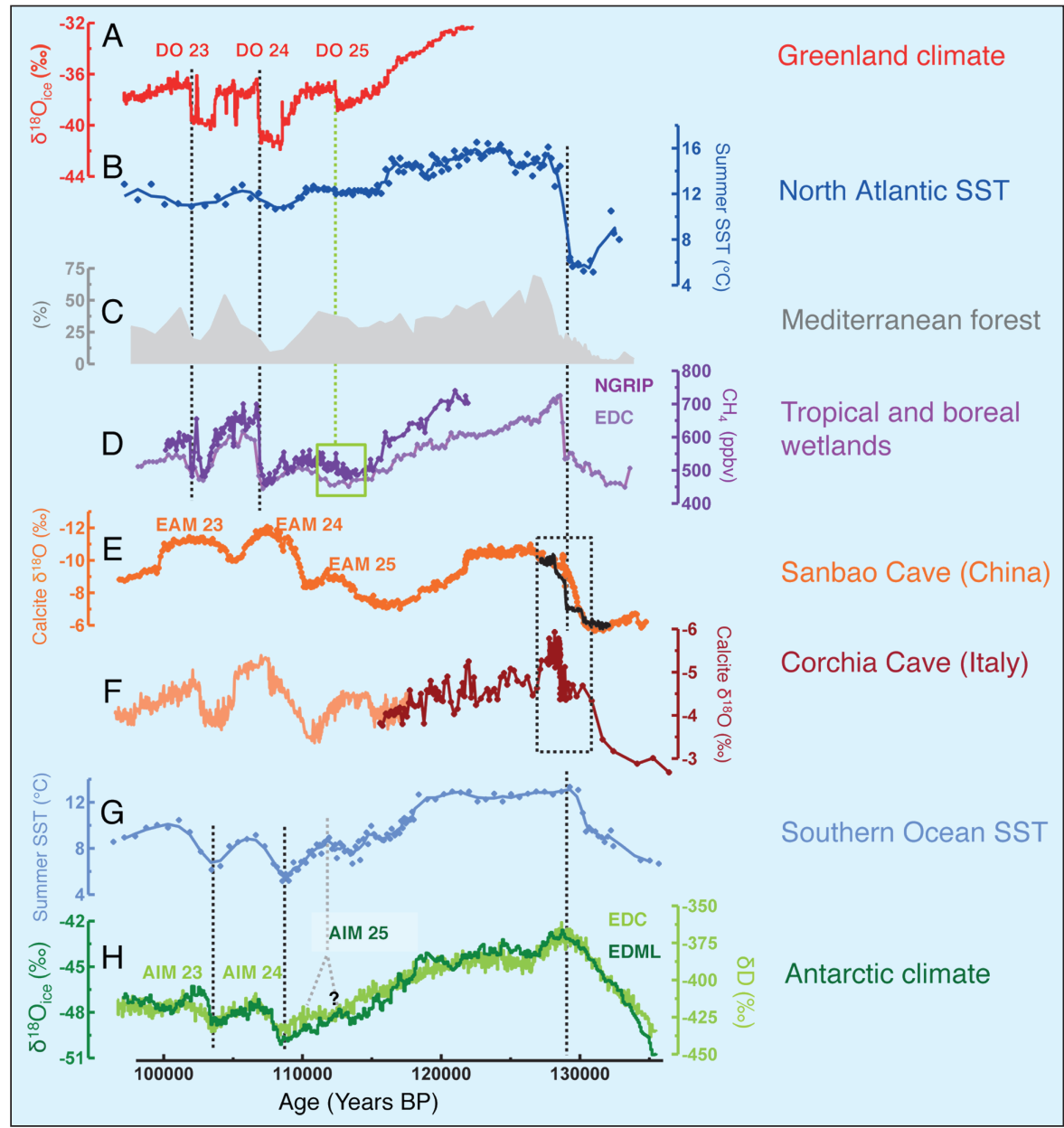

Figure 1: A) North GRIP $\delta^{18} \mathrm{O}$ (NorthGRIP Project members, 2004), B) Summer Sea Surface Temperature (SST) from ODP 980 marine core (Oppo et al. 2006), C) Temperate tree pollen percentages from MD95-2042 marine core (Shackleton et al. 2002), D) Atmospheric methane concentrations from NorthGRIP (Dark purple, Capron et al. 2010) and EDC (Light purple, Loulergue et al. 2008) ice cores, E) Speleothem $\delta^{18} \mathrm{O}$ from Sanbao Cave (orange, Wang et al. 2008; black, Cheng et al. 2009), F) Speleothem $\delta^{18} \mathrm{O}$ from Corchia Cave (brown, Drysdale et al. 2007; light orange, Drysdale et al. 2009), G) Summer SST from MD02-2488 marine core (Govin et al. 2012), H) EDC SD (Jouzel et al. 2007) and EDML $\delta^{18} \mathrm{O}$. (EPICA community members, 2006). All records are synchronized onto the EDC3 timescale except the speleothem records. Dashed lines highlight the unambiguous tie points used to synchronize marine records onto ice core records (Govin et al. 2012). The green rectangle and dashed line highlight the ambiguous signature of GIS 25 onset in the North GRIP methane concentration record (Capron et al. 2012). The black dashed rectangle highlights that the abrupt $\delta^{18} \mathrm{O}$, shift over Termination II is not synchronous in the various speleothem records. The yellow areas indicate the divergence between ice core and speleothem records in the age of Dansgaard-Oeschger (DO) events 23,24, and 25. The grey dashed lines point to the AIM 25 event as identified in the EDC (Jouzel et al. 2007) and in the EDML (Stenni et al. 2010) water isotopic profiles and illustrates the difficulty to define unambiguous pointers over the glacial inception. 
Mount Moulton volcanic event provides an absolute age constraint at $92.1 \pm 4.4$ ka BP (Dunbar et al. 2008) included in the EPICA Dome C timescale (hereafter, EDC3 timescale; Parrenin et al. 2007). In order to place additional constraints, orbital tracers $\left(\delta \mathrm{O}_{2} / \mathrm{N}_{2}\right.$, air content, $\left.\delta^{18} \mathrm{O}_{\mathrm{atm}}\right)$ have been implemented for ice core timescales (e.g. Dreyfus et al. 2007; Kawamura et al. 2007; Parrenin et al. 2007; Raynaud et al. 2007). But because the mechanisms behind these orbital tracers are yet to be fully understood (e.g. Landais et al. 2012; Dreyfus et al. 2007), the associated uncertainties are large (e.g. $6 \mathrm{ka}$ for $\delta^{18} \mathrm{O}_{\mathrm{atm}}$ ).

A close inspection of the last glacial inception and the succession of Greenland Stadials (GS) and Interstadials (GIS) reveals significant differences in the timescales of the onset of GIS 23, 24 and 25 as recorded in NorthGRIP $\delta^{18} \mathrm{O}_{\text {ice }}$ (Fig. $1 \mathrm{~A})$ and their counterparts in speleothem records from Corchia Cave (Drysdale et al. 2007, Fig. 1F) and Sanbao Cave (Cheng et al. 2009; Wang et al. 2008; Fig. 1E).

\section{Record synchronization}

Ice core synchronization is done on (1) the ice phase through identification of the same volcanic events (e.g. Parrenin et al. 2012) or ${ }^{10} \mathrm{Be}$ variability from different ice cores (Raisbeck et al. 2007), and (2) the gas phase through global atmospheric tracers (methane concentration, $\delta^{18} \mathrm{O}_{\mathrm{atm}}$ e.g. Blunier et al. 1998, Fig. 1D).

For example, a chronology for the EPICA Dronning Maud Land (EDML) ice records, coherent with the EDC3 timescale (as illustrated with the EDML and EDC water isotopic profiles on Figure $1 \mathrm{H}$ ) has been developed by synchronizing volcanic horizons and dust peaks from the EDML ice with EDC ones (Ruth et al. 2007; Severi et al. 2007). Subsequently, the NorthGRIP record has been put on the EDC3 age scale synchronizing the abrupt changes in $\mathrm{CH}_{4}$ concentration (Fig. 1D) and $\delta^{18} \mathrm{O}_{\text {atm }}$ variations linked to the DO events between 70 and 123 ka BP (Capron et al. 2010). However, this synchronization exercise has some limitations when clear methane concentration or $\delta^{18} \mathrm{O}_{\text {atm }}$ signatures are lacking (e.g. Capron et al. 2012; Fig. 1D, green square).

Direct correlation of the plateau of benthic foraminifera $\delta^{18} \mathrm{O}$ minimum values is commonly applied for synchronizing marine sediment records during the LIG (e.g. Cortijo et al. 1999). However, this method has limitations when considering records from different water depths and oceanic basins (Skinner and Shackleton 2005; Waelbroeck et al. 2011). An alternative synchronization approach would be based on the identification of tephra layers in marine sediment with a similar chemical composition (e.g. Rasmussen et al. 2003).

Changes in the Earth's magnetic field intensity are recorded in marine, terrestrial, and ice records (e.g. Raisbeck et al. 1987). While absolute dating of tephra layers and speleothems allow attribution of an absolute timescale to the Earth's magnetic field variations, the latter can then be used to link the various archives (e.g. Zhou and Shackleton 1999).

\section{Climatostratigraphic alignment}

While it is desirable to use global markers or joint analyses of different proxies within the same physical sequence (e.g. dust measured both in ice and marine cores), relative dating can sometimes only be derived indirectly from climatic records. Climatostratigraphic alignment is inevitably based on assumptions about the mechanisms linking climate and measurements. These underlying hypotheses have to be explicitly formulated.

Possible alignments between marine and ice core records are based on the hypothesis that Sea Surface Temperature (SST) changes in the sub-Antarctic zone of the Southern Ocean (respectively in the North Atlantic) occurred simultaneously with air temperature changes over inland Antarctica (respectively Greenland) (e.g. Govin et al. 2012; Shackleton et al. 2002). Figure $1(A-B, D, G-H)$ illustrates how this approach can produce a coherent relative timescale between marine and ice core records from both hemispheres (Govin et al. 2012). Age pointers were defined at the start of Termination II and over the millennial-scale events identified towards the end of the LIG (Fig. 1A-B, G-H). However, regional disparities in climatic event expression lead to a relative uncertainty of up to $1 \mathrm{ka}$ (Buiron et al. 2012). Also, it remains problematic to define precise tie points within the LIG (Govin et al. 2012) and one should limit the use of tie points to unambiguous climatic features.

At a regional scale, marine SST and speleothem records may be aligned on the principle that variations in regional SSTs, air temperatures, evaporation and moisture transport are synchronous, and ultimately affect speleothem $\delta^{18} \mathrm{O}$ signatures (e.g. Drysdale et al. 2009). These changes in moisture availability and air temperature should also affect synchronously terrestrial ecosystems. Such an approach could potentially be used to align speleothem and pollen records at the start and end of the LIG and within the LIG.
Cheng et al. (2006) suggested that abrupt calcite $\delta^{18} \mathrm{O}$ shifts from Chinese speleothems correlate to sharp methane concentration changes measured in ice cores that are associated with abrupt climate changes from the last glacial period and the last two climatic terminations. This hypothesis has been used to constrain the EDC3 timescale over Termination II (Parrenin et al. 2007; Fig. $1 D, E, H)$. However, the interpretation of speleothem $\delta^{18} \mathrm{O}$ and $\delta^{13} \mathrm{C}$ in terms of climatic or environmental parameters is not straightforward (e.g. Baker et al. 1997). In particular, the climatic interpretation of Chinese stalagmite $\delta^{18} \mathrm{O}$ has been recently challenged (Pausata et al. 2011; Wang and Chen 2012). Also, the question as to whether rapid calcite $\delta^{18} \mathrm{O}$ variations measured in Chinese speleothems are systematically synchronous with abrupt methane concentration increases requires further investigation (Fleitman et al. unpublished data).

\section{Perspectives}

The guidelines for dating and synchronization established so far aim for moving toward a coherent LIG dating. Within that context, a coherent timescale between several ice and marine records from both hemispheres has already been established (e.g. Capron et al. 2010; Govin et al. 2012).

Matching various paleo-records also requires assessing rigorously the coherence of the different dating methods and developing integrated techniques. For example, the EDC3 timescale will be replaced soon by AICC2012, a new Antarctic Ice Core Chronology derived from an inverse model that integrates and optimizes absolute and new relative constraints from several ice cores (Bazin et al. 2012).

The guidelines will be updated as new higher-resolution records emerge that may allow for increasing the number of chronological tie points over past interglacials through the identification of additional rapid events and the use of improved radiometric techniques (e.g. Aciego et al. 2010).

\section{Selected references}

Full reference list online under:

http://www.pages-igbp.org/products/newsletters/ref2013_1.pdf

Capron E et al. (2010) Quaternary Science Reviews 29: 222-234

Cheng H et al. (2009) Science 236: 248-252

Govin A et al. (2012) Climate of the Past 8: 483-507

Parrenin Fet al. (2007) Climate of the Past 3: 485-497

Shackleton NJ, Hall MA, Vincent E (2000) Paleoceanography 15: 565-569 